\title{
Posttonsillektomi kanama: Çocuklar ve yetişkinler arasındaki farklar
}

\section{Posttonsillectomy bleeding: Difference between children and adults}

\author{
Ceyhun Aksakal ${ }^{1}$
}

${ }^{1}$ Tokat Devlet Hastanesi, Kulak Burun Boğaz Bölümü

öz.

Amaç: Tonsillektomi veya adenotonsillektomi yapılan erişkin ve çocuk hastalarda görülen posttonsillektomi kanamaların (PTK) özelliklerini incelemek ve karşıllaştırmak

Materyal ve Metod: Bu retrospektif kesitsel çalışmada 1 Ocak 2014 ile 30 Eylül 2018 arasında Tokat Devlet Hastanesinde bipolar elektrokoter ile tonsillektomi veya adenotonsillektomi yapılan 421 hastanın elektronik medikal kayıtları incelendi. Hastaların yaş, cinsiyet, uygulanan cerrahi prosedürler, PTK' nın gerçekleştiği gün, PTK için kan transfüzyonu gerekliliği, PTK da hemostazın tipi gibi özellikleri değerlendirildi.

Bulgular: PTK, erişkinlerde (yaş ₹16) \%6,10, çocuklarda (yaş<16) \% 2,41 oranında görüldü. Primer PTK bir erişkin hastada görülürken,çocuk hastalarda primer PTK görülmedi. Sekonder PTK erişkinlerde sekiz $(\% 6,10)$ hastada görülürken, çocuklarda yedi $(\% 2,41)$ hastada görüldü. PTK insidansı erişkinlerde çocuklara göre anlamlı düzeyde yüksek bulundu $(p<0,05)$. Kan tranfüzyonu ihtiyacı iki erişkin PTK'ı hastada olurken, çocuk hastalardaki PTK' ların hiçbirinde kan transfüzyonu ihtiyacı olmadı. PTK görülen yedi çocuk hastanın üçünde spontan hemostaz görülürken, dört hastada hemostaz genel anestezi altında sağlandı. PTK görülen 9 erişkin hastanın birinde spontan hemostaz görüldü. Altı hastada ise hemostaz genel anestezi altında sağlandı.

Sonuç: Erişkinlerde PTK çocuklara göre daha fazla görülmektedir. Genel olarak PTK nın en sık görüldüğü günler postoperatif 6.-8. Günler arasıdır. Spontan hemostaz çocuklarda erişkinlere göre daha fazla görülürken, çocuklardaki PTK da genel anestezi altında hemostaz oranı daha yüksektir.

Anahtar Sözcükler: Posttonsillektomi kanama; Tonsillektomi; Çocuk; Erişkin

\section{Abstract}

Background: To examine and compare the characteristics of posttonsillectomy bleeding (PTB) in adult and pediatric patients who underwent tonsillectomy or adenotonsillectomy.

Methods: In this retrospective cross-sectional study, medical records of 421 patients who underwent bipolar elecrtocautery with tonsillectomy or adenotonsillectomy in Tokat State Hospital between 1 January 2014 and 30 September 2018 were examined. The characteristics of the patients such as age, gender, surgical procedures performed, the day of PTB, necessity of blood transfusion for PTB, type of hemostasis in PTB were evaluated.

Results: PTB was $6.10 \%$ in adults (age $\geqslant 16$ ) and $2.41 \%$ in children (age $<16$ ). While PTB was seen in an adult patient, primary PTB was not seen in pediatric patients. Secondary PTB was seen in eight (6.10\%) patients in adults and in seven (2.41\%) patients in children. The incidence of PTB was significantly higher in adults than in children $(p<0.05)$. The need for blood transfusion was in two adult patients with PTB, but none of the PTBs required blood transfusion in pediatric patients. Spontaneous hemostasis was seen in three of seven children with PTB, and hemostasis was performed in four patients under general anesthesia. Spontaneous hemostasis was observed in one of the nine adult patients with PTB. In six patients, hemostasis was performed under general anesthesia.

Conclusions: PTB is more common in adults than in children. In general, the most common days of PTB are postoperative 6.-8. days. Spontaneous hemostasis is more common in children than in adults, whereas in children, PTB has a higher rate of hemostasis under general anesthesia.

Keywords: Posttonsillectomy bleeding; Tonsillectomy; Child; Adult

\section{Sorumlu Yazar I Corresponding Author}

Dr. Ceyhun Aksakal

Tokat Devlet Hastanesi, Kulak Burun Boğaz Bölümü

\section{Tel: 05415470353}

E-mail: aksakalceyhun@gmail.com

Geliş tarihi / Received: 17/03/2019

Kabul tarihi / Accepted: 24/06/2019

DOI: $10.35440 /$ hutfd. 541040 


\section{Giriş}

Tonsillektomi Kulak Burun Boğaz uzmanları tarafından en sık yapılan cerrahi girişimlerden biridir. Rekürren tonsillit, obstrüktif uyku apnesi, yutma güçlüğü ve solunum güçlüğü tonsillektominin endikasyonları arasındadır. Tonsillektomi sonrası görülebilen komplikasyonlar arasında ağrı, tonsil lojunda kanama, havayolu obstrüksiyonu, dehidratasyon ve pulmoner ödem gibi durumlar vardır. Posttonsillektomi kanama (PTK) nadir fakat hayatı tehdit edebileceği için oldukça önemli bir komplikasyondur (1). PTK tonsillektomi sonrası en korkulan komplikasyondur. Sıkıkla tekrar hastaneye başvuru gerektirir (2). Primer PTK tonsillektomi operasyonundan sonraki lik 24 saatte gerçekleşen ve tonsil lojundan kaynaklanan kanamadır. Sekonder PTK ise 24 saatten sonra gerçekleşen PTK'dır. PTK insidansı literatürde \%6-15 oranında bildirilmiştir (3). Tonsillektomide kullanılan klasik teknik, soğuk bıçak tonsillektomi iken son yillarda bipolar elektrokoter, koblasyon, harmonik skalpel ile tonsillektomi de yaygınlaşmıştır. Bipolar elektrokoter, intraoperatif kanama miktarı ve operasyon zamanını kısaltan bir enstrüman olması ile ön plana çıkmıştır (4). Ayrıca bipolar elektrokoter ile yapılan tonsillektomi sonrasında primer PTK insidansının soğuk bıçak tonsillektomiye göre daha az, buna karşın sekonder PTK oranının daha yüksek olduğu bildirilmiştir(3). Bipolar diyatermi ile tonsillektomi özellikle 1990' Iı yillardan sonra popülarite kazanmış ve hızla yaygınlaşmıştır(5). Popülasyon bazlı geniş ulusal çalışmalar yetişkinlerde PTK' nın çocuklara oranla daha yüksek olduğunu göstermektedir (6). Tekniklere göre bakıldığında soğuk bıçak tonsillektomi de yetişkinlerde PTK çocuklara göre daha yüksek bulunmuştur (7). Erişkinler ve çocukları PTK açısından karşılaştıran çalışmalar literatürde oldukça azdır. Bu çalışmanın amacı erişkin ve çocuklarda görülen tonsillektomi sonrası kanamaların özelliklerini araştırmak ve fakkıııları incelemektir.

\section{Materyal ve Metod}

$\mathrm{Bu}$ çalışma için lokal etik kuruldan onay alınmıştır. Bu retrospektif, kesitsel çalışmada Tokat Devlet Hastanesinde 1 Ocak 2014 ile 30 Eylül 2018 arasında bipolar elektokoter ile tonsillektomi veya adenotonsillektomi yapılan 421 (216 kadın, 205 erkek) hastanın elektronik medikal kayıtları değerlendirildi. Hastaların tümü sık tekrarlayan tonsillit ve/veya üst hava yolu obstrüksiyonu endikasyonu ile tonsillektomi ve/veya adenotonsillektomi yapılan hastalardan oluşmuştur. Tüm hastaların ortalama yaşı 13,22 \pm 10,11 (2-61) olarak bulundu. Tonsillektomi $145(\% 34,44)$ hastada yapilırken, adenotonsillektomi $276(\% 65,56)$ hastada yapıldı. Son iki hafta içinde üst solunum yolu enfeksiyonu geçirmiş olan hastalarda cerrahi işlem uygulanmadı. Ayrıca postoperatif dönemde adenoid kanaması olan hastalar çalışma dışı bırakııdı. Tüm hastalar standart olarak postoperatif 1 . gün taburcu edildi ve 1 . hafta ve 1. ay kontrole çağırıldı.

\section{Cerrahi teknik}

Tüm hastalarda endotrakeal entübasyonu takiben genel anestezi altında tonsillektomi veya adenotonsillektomi operasyonu yapıldı. Her iki grupta da bipolar elektrokoter ile tonsil dokusu diseke edildi ile extrakapsüler tonsillektomi yapıldı. Tüm hastalarda tonsil lojundaki hemostaz bipolar elekrokoter ile sağlandı.

\section{Yaşa göre gruplama ve postoperatif tonsil kanaması- nın değerlendirilmesi}

Hastalar yaş gruplarına göre ikiye ayrıldı. 16 yaşından küçük hastalar ( $n=290, \% 68,88)$ çocuk yaş grubunda, 16 yaş ve daha büyük hastalar $(n=131, \% 31,12)$ erişkin yaş grubunda değerlendirildi.

Postoperatif dönemde gerçekleşen ve tonsil lojundan kaynaklanan kanamalar PTK olarak değerlendirildi. Primer PTK postoperatif 24 saat içindeki kanama, sekonder PTK ise postoperatif 24 saat ile 30 gün arası olan kanama olarak değerlendirildi. PTK' nın görülme günleri değerlendirildi. Yetişkin ve çocuklarda hemostazın şekli (Spontan hemostaz, Lokal müdahale ile hemostaz, genel anestezi ile hemostaz) kan transfüzyonu gerekliliği her iki grupta değerlendirildi ve karşılaştııılı.

\section{İstatistiksel analiz}

PTK nın erişkin ve çocuklar arasında istatistiksel olarak karşıllaştırımasında ve cinsiyetlere göre PTK oranlarının istatistiksel karşılaştııımasında Ki-kare testi kullanıldı. $P<0,05$ değeri tüm istatistiksel karşılaştırmalarda anlamlı kabul edildi.

İstatistiksel analizde Statistical Package fort the Social Sciences (SPSS), version 21.0 (SPSS Inc., Chicago, IL, US) kullanıldı.

\section{Bulgular}

Yaklaşık 5 yıllık süreçte 421 (216 kadın, 205 erkek) hastaya tonsillektomi veya adenotonsillektomi uygulandı. PTK erişkinlerde çocuklara göre anlamlı düzeyde yüksek bulundu $(p<0,05)$ (Tablo 1). PTK nın yaş ve cinsiyetlere göre dağıımı Tablo 1 de gösterilmiştir.

421 hasta arasında bir $(\% 0,23)$ hastada primer PTK görülürken, $15(\% 3,56)$ hastada sekonder PTK görüldü. Primer PTK bir erişkin hastada görülürken, çocuk hastalar arasında primer PTK görülmedi. Sekonder PTK 290 çocuk hastanın yedisinde görülürken (\%2,41) , 131 erişkin hastanın sekizinde $(\% 6,10)$ görüldü. PTK' nın en sık görüldüğü yaş aralığı 17-20 (\%11,76) olarak bulunmuştur (Tablo 2). Yaş gruplarına göre dağılım Şekil 1 de gösterilmiştir.

Kan tranfüzyonu ihtiyacı iki erişkin PTK'lı hastada olurken, çocuk hastalardaki PTK' ların hiçbirinde kan transfüzyonu intiyacı olmadı.

Primer PTK görülen bir hastada kanama hastanede yatış esnasında operasyon günü olurken, sekonder PTK görülen hastaların tümü acil servise başvurmuştu. PTK görülen yedi çocuk hastanın tümü serviste takip edildi. Yedi 
hastanın üçünde spontan hemostaz izlendi. Yedi çocuk hastanın dördüne genel anestezi altında müdahale edildi. PTK görülen 9 erişkin hastadan ikisinde hemostaz direkt bakı ile lokal anestezi ile bipolar diyatermi ile sağlanırken bir hastada spontan hemostaz izlendi. Altı erişkin PTK'lı hastada hemostaz genel anestezi altında sağlandı.

Çocuk hastalarda görülen sekonder PTK en çok 6. ve 7. günlerde görülürken ortalama görülme günü 6,5 'di. Erişkin hastalarda PTK en sık 7. günde görülürken ortalama görülme günü 7,11 olarak bulundu (Şekil 2).

Tablo 1. Posttonsillektomi kanamaların yaş gruplarına ve cinsiyete göre dağılımı

\begin{tabular}{lcccc}
\hline & Toplam & PTK(+) & PTK(-) & $p$ değeri $^{*}$ \\
\hline Yaş grubu & 421 & & & \\
Çocuk & 290 & 7 & 283 & $<0,05$ \\
Erişkin & 131 & 9 & 122 & \\
\hline Cinsiyet & 421 & & & \\
Erkek & 205 & 7 & 198 & 0,686 \\
Kadın & 216 & 9 & 207 & \\
\hline Çocuk & 290 & & & \\
Erkek & 129 & 3 & 126 & 0,930 \\
Kadın & 161 & 4 & 157 & \\
\hline Erişkin & 131 & & & \\
Erkek & 50 & 3 & 47 & 0,757 \\
Kadın & 81 & 6 & 75 & \\
\hline
\end{tabular}

*: Ki-kare testi, PTK: Posttonsillektomi kanama

Tablo 2. Posttonsillektomi kanamaların kanama türü, kan transfüzyonu ihtiyacı ve hemostaz tipine göre yaş grupları ve cinsiyet açısından değerlendirilmesi

\begin{tabular}{|c|c|c|c|c|c|c|}
\hline \multicolumn{4}{|c|}{ Kanama Türü } & \multicolumn{3}{|c|}{ Hemostaz } \\
\hline Gruplar & $\begin{array}{l}\text { Primer } \\
\text { PTK }\end{array}$ & $\begin{array}{l}\text { Sekonder } \\
\text { PTK }\end{array}$ & $\begin{array}{l}\text { Kan Trans- } \\
\text { füzyonu }\end{array}$ & Spontan & Lokal & $\mathrm{GA}$ \\
\hline \multicolumn{7}{|l|}{$\begin{array}{c}\text { Çocuk } \\
(n=290)\end{array}$} \\
\hline $\begin{array}{c}\text { Kadın } \\
(n=129)\end{array}$ & - & 4 & - & 1 & - & 2 \\
\hline $\begin{array}{c}\text { Erkek } \\
(n=161)\end{array}$ & - & 3 & - & 2 & - & 2 \\
\hline Toplam & - & 7 & - & 3 & - & 4 \\
\hline \multicolumn{7}{|l|}{$\begin{array}{c}\text { Erişkin } \\
(n=131)\end{array}$} \\
\hline $\begin{array}{l}\text { Kadın } \\
(n=81)\end{array}$ & - & 6 & 1 & 1 & 1 & 3 \\
\hline $\begin{array}{c}\text { Erkek } \\
(n=50)\end{array}$ & 1 & 2 & 1 & - & 1 & 3 \\
\hline Toplam & 1 & 8 & 2 & 1 & 2 & 6 \\
\hline $\begin{array}{l}\text { Toplam } \\
\text { (Tüm } \\
\text { hastalar) }\end{array}$ & 1 & 15 & 2 & 4 & 2 & 10 \\
\hline
\end{tabular}

GA: Genel anestezi, PTK: Posttonsillektomi kanama

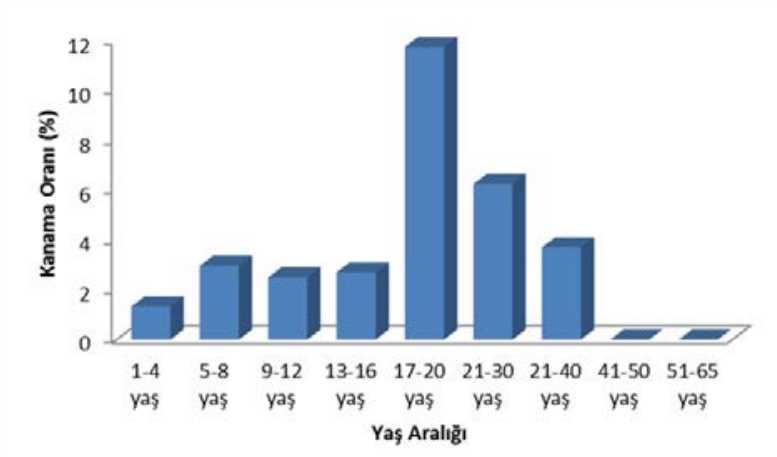

Şekil 1. Postonsillektomi kanama oranlarının yaş gruplarına göre dağılımı

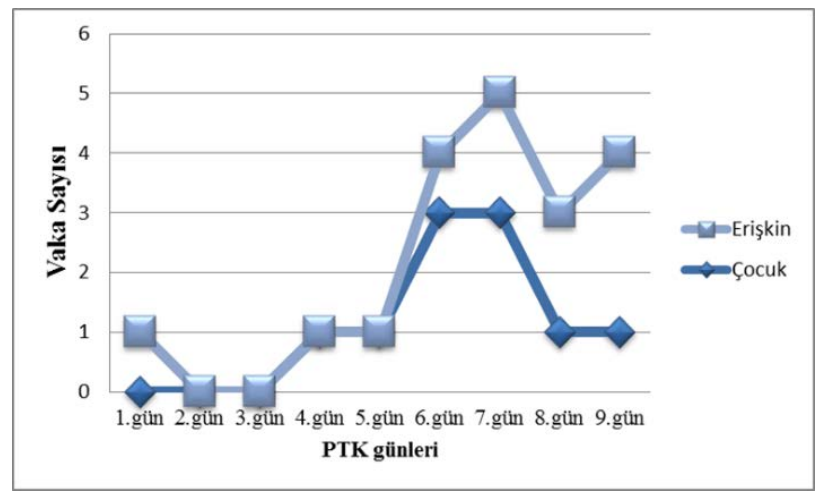

Şekil 2. Postonsillektomi kanamaların kanama günlerine göre yaş grupları arasındaki dağılımı

PTK: Posttonsillektomi kanama

\section{Tartışma}

PTK primer ve sekonder olarak ikiye ayrılır. Primer PTK ilk 24 saatte olan tonsil lojundan olan kanama iken sekonder kanama 24 saat ile 30 gün arası olan PTK olarak tanımlanmaktadır. Önceki çalışmalar primer PTK nın sekonder PTK ya oranla daha az görüldüğünü göstermektedir. Primer PTK insidansı \%0,2-\%2,2 arasında değişmekteyken, sekonder PTK insidansı \%0,1-\%4,8 arasında değişmektedir $(8,9)$. Torres ve ark. 326 hastadan oluşan erişkin tonsillektomi serisinde 3 hastada primer PTK gözlemlerken 14 hastada sekonder kanama gözlemlemişlerdir (10). Lee ve ark. toplam 349 hastadan oluşan tonsillektomi serisinde bir hastada primer PTK gözlemlerken, 32 hastada sekonder PTK gözlemlemişlerdir (7). Ayrıca onların çalışmasında yetişkinlerde primer PTK gelişmemişken, 23 yetişkinde sekonder PTK gözlenmiştir. Bizim çalışmamızda ise primer PTK bir yetişkin hastada görülürken çocuk hastalarda primer PTK görülmemiştir. Lee ve ark.nın çalışmasında ayrıca bipolar elektrokoter ile tonsillektomi yapılan hastalarda yetişkinlerde sekonder PTK çocuklara oranla istatistiksel olarak yüksek bulunmuştur (7). Bizim çalışmamızda da önceki çalışmalarla $(7,11,12)$ korele biçimde yetişkinlerde sekonder PTK çocuklara oranla yüksek bulunmuştur. Yetişkinlerde PTK nın neden fazla görüldüğü konusunda kesin bir veri olma- 
sa da bu durum daha çok yetişkinlerde tonsil lojunu besleyen vasküler yapıların büyüklüğüne ve yetişkinlerde sosyal aktivitenin postoperatif dönemde yüksek olmasına bağlanmıştı (13). Çalışmamızda yetişkinlerde PTK nın en sık görüldüğü yaş aralığı olarak 16-20 olması bu hipotezi desteklemektedir.

Sekonder PTK' ların en çok görüldüğü günler 5-7 günler arasıdır $(6,8,10)$. Kim ve ark. PTK' nın en sık 6. ve 8. günler arasında görüldüğünü bildirmişlerdir (13). Aynı çalışmada çocuklarda 11. Gün civarında ikinci bir kanama artışı gözlenmiştir (13).Özellikle çocuklarda tonsil kanamasının 11 ve 12. günlerde ikinci bir yapmasının nedeni açıklanamamıştır. Bizim çalışmamızda Kim ve ark çalışmasından farklı olarak çocuklarda 10. Günden sonra ikinci bir pik gözlenmemiştir. Fakat önceki çalışmalarla benzer olarak çocuklarda ve erişkinlerde kanamanın en sık görüldüğü günler olarak 6 . ve 8 . günler arası olarak bulunmuştur.

Çalışmamızda tüm hastalarda kanama oranı $\% 3,8$ olarak bulunmuştur. PTK oranı farklı çalışmalarda \%2,7 ile $\% 15,9$ arasında bulunmuştur (14). 13554 hastayı kapsayan ulusal, prospektif bir çalışmada primer PTK $\% 0,5$ oranında görülürken, sekonder PTK \% 2,9 oranında görülmüştür (15). Torres ve ark. nın çalışmasında bipolar elektrokoter ile yapılan tonsillektomi sonrası kanama oranı çocuklarda $\% 3$, yetişkinlerde $\% 10,3$ bulunmuştur (10). Bizim çalışmamızda ise PTK çocuklarda \%2,4, yetişkinlerde $\% 6,8$ oranında bulunmuştur.

PTK' da çocuklar ve erişkinler arasındaki önemli farklardan biri de kanama kontrolünün tipidir. PTK ile başvuran bir hastada genel prensip olarak oral muayenede tonsil lojunda kan pıhtısı görülürse ilk olarak tonsil loju pıhtılardan temizlenir. Eğer hastada aktif kanama görülürse ilk olarak lokal anestezi altında müdahale edilmesi, hemostaz sağlanamazsa hastanın ameliyata alınarak müdahale edilmesi önerilmektedir (13). Önceki çalışmaların sonuçları PTK görülen çocuklarda spontan hemostazın yetişkinlere göre daha yüksek olduğunu göstermektedir (13). Bizim çalışmamızda da benzer şekilde çocuklarda PTK da spontan hemostaz oranı yetişkinlere göre daha yüksek bulunmuştur. Hemostaz konusundaki bu farklıık çocuklar ve yetişkinler arasındaki tekrarlayan tonsillit oranlarının farklılığına bağlanmıştır (16).Spontan hemostaz konusundaki farklıı̆ın nedenlerinden biri de yetişkinlerde çocuklara göre tonsil dokusunu besleyen vasküler ağın fazla olması ve damar çaplarının daha geniş olmasına bağlı olabilir. Çalışmamızın ilginç sonuçlarından biri de çocuk hastalarda PTK da hiçbir hastada lokal anestezi ile hemostaz sağlanmamış olmasıdır. Bu durumun nedeni çocuk hastalarda bu işlemin uygulanma güçlüğü olabilir. Çocuk hastalarda aktif kanama izlenen durumlarda rutin olarak ilk önce lokal anestezi altında hemostaz sağlamayı denesek de hiçbir hastada bu mümkün olmamıştır. Aynı zamanda oral kavitenin yetişkinlere göre küçük olması ve çocuk hastalarda lokal anesteziye uyumsuzluk bu durumun nedeni olabilir. Çocuklarda tonsil kanaması esnasında aspirasyon riskinin erişkinlere göre yüksek olmasından dolayı bize göre spontan hemostaz izlenmeyen durumlarda hastaya genel anestezi altında hızla müdahale planlanmalıdır.

Çalışmamızda PTK için çocuklar ve yetişkinler arasındaki önemli farklardan biri de kan transfüzyonu gerekliliğidir. Çalışmamızda çocuk hastalardaki PTK'ların hiçbirinde kan transfüzyonu gereksinimi olmazken iki yetişkin hastada kan transfüzyonu yapıımıştır. Attner ve ark. çalışmalarında pediatrik hastalarda rekürren PTK görülen hastaları incelemişlerdir.Onlar çalışmalarında 21 rekürren PTK Iı hastanın ikisinde operasyonda kan tranfüzyonu intiyacı olduğunu bildirmişlerdir(17). Walker ve ark.monopolar diatermi ile soğuk bıçak tonsillektomi yapılan hastalardaki postoperatif kanama miktarı ve diğer kanama özelliklerini incelediği 1133 hastalık çalışmalarında hastalık çalışmasında dört hastada kan transfüzyonu gerekliliği bildirmiştir(18). Aynı çalışmada soğuk bıçak tonsillektomi yapılan hastalardan hiçbirinde kan tranfüzyonu gerekliliği bildirilmemiştir.

Çalışmamızda karşılaştııılan gruplarda sayıların birbirine yakın olmaması bu çalışmanın kısıtıııklarından biridir.Bunun en büyük nedeni çalışmanın retrospektif dizaynıdır. Diğer bir kısıtılık ise çalışmadaki hastaların sayısıdır. Prospektif özellikli ve daha fazla hasta grubunu kapsayacak çalışmalar PTK ile daha fazla veri elde edilmesini sağlayabilir.

Sonuç olarak, erişkinlerde PTK çocuklara göre daha fazla görülmektedir. Genel olarak PTK nın en sık görüldüğü günler postoperatif 6.-8. Günler arasıdır. Spontan hemostaz çocuklarda erişkinlere göre daha fazla görülürken, çocuklardaki PTK da genel anestezi altında hemostaz oranı daha yüksektir.

\section{Kaynaklar}

1. Çakır A, Boran C, Olgun Y, Erdağ TK, Post-tonsillectomy bleeding: Our 10-year experience. Kulak Burun Bogaz Ihtis Derg 2017;27(1):1-9

2. Odhagen $E$, Sunnergren $O$, Söderman $A H$, Thor J, Stalfors J. Reducing post-tonsillectomy haemorrhage rates through a quality improvement project using a Swedish National quality register: a case study. Eur Arch Otorhinolaryngol. 2018;275(1):1631-9.

3. Kim DW, Koo JW, Ahn SH, Lee CH, Kim JW. Difference of delayed post-tonsillectomy bleeding between children and adults. Auris Nasus Larynx. 2010 ;37(4):456-60.

4. Dadgarnia MH, Aghaei MA, Atighechi S, Behniafard N, Vahidi MR, Meybodian $\mathrm{M}$, et al. The comparison of bleeding and pain after tonsillectomy in bipolar electrocautery vs cold dissection. Int J Pediatr Otorhinolaryngol. 2016;89(9):38-41.

5. Blanchford H1, Lowe D. Cold versus hot tonsillectomy: state of the art and recommendations. ORL J Otorhinolaryngol Relat Spec. 2013;75(3):136-41.

6. Østvoll $E$, Sunnergren $O$, Stalfors $J$. Increasing Readmission Rates for Hemorrhage after Tonsil Surgery: A Longitudinal (26 Years) National Study. Otolaryngol Head Neck Surg. 2018 ;158(1):167-76. 
7. Lee MS, Montague ML, Hussain SS. Post-tonsillectomy hemorrhage: Cold versus hot dissection. Otolaryngol Head Neck Surg. $2004 ; 131(6): 833-6$.

8. Francis DO, Fonnesbeck $C$, Sathe N, McPheeters M, Krishnaswami S, Chinnadurai S. Postoperative bleeding and associated utilization following tonsillectomy in children: a systematic review and meta-analysis. Otolaryngol Head Neck Surg 2017;156(3):442-55.

9. Windfuhr JP, Chen YS, Remmert $\mathrm{S}$. Hemorrhage following tonsillectomy and adenoidectomy in 15,218 patients. Otolaryngol Head Neck Surg 2005;132(2): 281-6.

10. Galindo Torres BP, De Miguel García F, Whyte Orozco J. Tonsillectomy in adults: Analysis of indications and complications. Auris Nasus Larynx. 2018 ;45(3):517-21.

11. Klug TE, Ovesen T. Post-tonsillectomy hemorrhage: incidence and risk factors. Ugeskr Laeger 2006;168(26-32):2559-62.

12. Carmody D, Vamadevan T, Cooper SM. Post tonsillectomy haemorrhage. J Laryngol Otol 1982;96(7):635-8.

13. Kim DW, Koo JW, Ahn SH, Lee CH, Kim JW.Difference of delayed post-tonsillectomy bleeding between children and adults. Auris Nasus Larynx. 2010 ;37(4):456-60.

14. Benninger $M$, Walner $D$. Coblation: improving outcomes for children following adenotonsillectomy. Clin Cornerstone. 2007;9(Suppl 1):13-23.

15. Lowe D, van der Meulen J. Tonsillectomy technique as a risk factor for postoperative haemorrhage. Lancet 2004;364(9435):697-702.

16. Heidemann $\mathrm{CH}$, Wallen $M$, Aakesson $M$, Skov $P$, Kjeldsen $A D$, Godballe C. Post-tonsillectomy hemorrhage: assessment of risk factors with special attention to introduction of coblation technique. Eur Arch Otorhinolaryngol 2009;266(9):1011-5.

17. Attner P, Haraldsson PO, Hemlin C, Hessén Soderman AC. A 4year consecutive study of post-tonsillectomy haemorrhage. ORL J Otorhinolaryngol Relat Spec. 2009;71(5):273-8.

18. Lowe D, Cromwell DA, Lewsey JD, Copley LP, Brown P, Yung M, et al. Diathermy power settings as a risk factor for hemorrhage after tonsillectomy. Otolaryngol Head Neck Surg. 2009 ;140(1):23-8. 